\title{
The use of the psycho-pedagogical approach in regulatory diagnostics of physical readiness of the students' youth
}

\author{
Aleksandr Boldov ${ }^{1, *}$, Aleksei Gusev ${ }^{1}$, Viktor Sharagin ${ }^{1}$, and Galina Afonina ${ }^{1}$ \\ ${ }^{1}$ Moscow State University of Psychology and Education, 127051, 29 Sretenka str., Moscow, Russia
}

\begin{abstract}
Based on the executed experiment, guidelines on introduction of the psycho-pedagogical approach in regulatory diagnostics of physical fitness of students are provided in the paper that, in our opinion, demonstrates the novelty of the approach to teaching disciplines "Physical culture" and "Applied physical culture", and a departure from strictly regulated dogmatics, the impact of the classical system of physical and sports training of the students' youth based on the diagnostic procedures in the attestation of students.
\end{abstract}

\section{Introduction}

Since 2007, a necessity to use the competence approach when teaching bachelors and specialists (physical culture as a discipline touches upon only these two levels of higher education) has emerged in the in the sphere of higher education in the Russian Federation. It has led to the development of the new competence standards of higher professional education, the standards of the 3rd generation, which closer correspond to the regulations of the Bologna process, according to the Sorbonne Joint Declaration [5].

In the higher school of Russia, before introduction of the competence approach in the standardization of educating bachelors and specialists, the activity in the sphere of physical culture and sports was defined based on a number of documents, in which accentuation of the activities and normative attestation of physical readiness were focused on the general physical fitness (GPF) [6,7].

According to the psycho-pedagogical approach in training and education of students in the field of physical culture, it is necessary to create wider "... specialized educational and correctional conditions..." [8], that naturally address us to the necessity to expand the regulatory basis of physical fitness of the students' youth by introducing there possibilities of variational realizations leading to a more complete disclosure of the internal and external "I" of psychology students.

In addition to that, at the contemporary stage of the development of the higher school in the Russian Federation, the professional applied training is the background of the curriculum of physical education of the students in higher educational establishments. The

* Corresponding author: volhv2000@ hotmail.com 
period of studying in the adolescence and young adulthood coincides with active formation of the spiritual and physical qualities of a person, and with preparation for implementing social functions in the situation of socio-economic development of the society. Physical education is an integral part of the educational process and cannot be considered as its secondary component.

The problem of formation of the motor activity of students has an important hygienic value since lately an increasing hypodynamia has been registered for the young people that is conditioned by the huge volume of study not only in auditoriums, but also at home $[1,2,3]$

The preservation and strengthening of health of the students' youth is one of the most important tasks of the state. However, students of the most of the higher educational establishments are used to be absent on the physical culture classes explaining their absenteeism by a number of reasons related to their own emotional and volitional sphere [3].

\section{Problem Statement}

Students accepted by the higher educational establishments are not often well prepared both emotionally and physically to the requirements that are demanded by the higher school. According to the data of numerous studies, up to $50-70 \%$ of people have some deviations in their health status at the time of graduation from schools $[1,2,3]$. In subsequent years of studying, they come to the full understanding of a responsibility they face during their study in a higher educational establishment. In current economic situation, students have to work since their early years of study. This work often does not correspond to the profile of their specialty that in turns leads a decrease of attendance of classes in physical culture from a year to a year. Such a trend is seen in all disciplines delivered in the higher school and leads to the increase of academic debts, especially in the discipline "Physical culture". Since this discipline is mostly presented by practical classes, where a student is to be present, it causes a problematic situation at the time of the examination sessions. The outdated approaches to the implementation of tasks of the physical education that have been inherited from the old system designed in the deeply ideologized structure of the Soviet pedagogics with its major priority on the united for all requirements for implementing the control standards (like the system of GTO, etc.) is another factor impacting the interest to the classes, and respectively, the academic performance of students [4]. Sometimes, they have been implemented to the detriment for the health of students or distorted the actual situation because of the "attributes." Currently, from that system we received, first, the system of organization of physical education in the higher educational establishments, secondly, the system of toughly regulated, average, control standards, and thirdly, the absolute sureness of teachers that the system of the control standards is the major measurable indicator for assessing a student, together with the attendance. Just rare representatives of the teaching personnel, who have a creative approach in their work (unfortunately, there are just few of them), broaden the regulatory framework in their work, and assess students not in accordance with some numerical characteristics of the passed standards during semesters, but, at least, according to the dynamics of their personal achievements.

In the work with students of the higher educational establishments on the subject "Physical culture" and assessing their achievements, a kind of one-dimensional approach is prevailing - a teacher bases on the average meaning of the standard indicator. The major criterion for obtaining credit is an attendance of classes under fear of not receiving it [4]. It reveals a problem of the doomed need to attend classes in physical culture in the higher educational establishment because this course is in the curriculum. Another aspect impacting the attendance are conditions, in which students have their classes - lack of good 
equipment in the departments, absence of gymnasiums, changing rooms and showers, exercise equipment and inventory that in turn negatively affect the attempts of teachers to create a comfort environment during the classes. The general attitude of students, their mentality of customers that is expressed in a negligent treatment of the material and technical base (gymnasiums, changing rooms and showers, exercise equipment and inventory), also has a significant meaning. After all, it is necessary to change the thesis, firmly rooted in the minds of students, that the use for free gives them right to negligence [1].

\section{Research Questions}

According to this field of the research, that includes the facts that absenteeism of classes in physical culture by the students prevents receiving the automatic credits in the discipline, there are strictly regulated procedures of the diagnostics of performance in the physical culture as standards in different kinds of sport, and that there are not always comfortable conditions for classes at the disposal of the departments of physical culture, we have assigned the following research tasks:

1. Is it possible to use the psycho-pedagogical approach for the attestation of students on the discipline "Physical culture"?

2. Is it possible to use the psycho-pedagogical approach in the regulatory diagnostics of the physical readiness of students as a method of more variational disclosure of the internal and external "I" of students?

3. Which standards in the physical fitness available in the attestation requirements are more preferable for the students of psychology?

\section{Purpose of the Study}

The purpose of this research is to analyze preferences of students in the regulatory diagnostics of study of the discipline "Physical culture" in the curriculum of the higher educational establishments with the use of the psycho-pedagogical approach.

The novelty of this research is in the fact that in the process of study of the disciplines "Physical culture" and "Applied physical culture" by students, the professors and teachers have to propose more variational approach to the regulatory diagnostics of the physical state and physical fitness of the students based on the students' emotional and volitional sphere.

We see the relevance of this study in utilization of the psycho-pedagogical approach with the variational methods of the regulatory diagnostics of the physical readiness of the students' youth, the future specialists in the pedagogical psychology.

\section{Research Methods}

283 girls and 101 young men, students of the 1st to the 3rd years, participated in the experiment on utilization of the psycho-pedagogical approach to the regulatory diagnostic procedures. In accordance with the psycho-pedagogical approach, in the process of study of the courses of "Physical culture" and "Applied physical culture" for creation of special educational and adjustment conditions, students have been proposed some requirements in the beginning of the academic year, namely:

1. The level of attendance of the discipline of $50 \%$ or more would be needed for automatic crediting and exemption from control standards in connection with the successful study of the course of the discipline (according to the specifics of a discipline). 
2. Delivery of control standards for disciplines would be executed in the final three weeks of the period of study defined by the workplans and thematic teaching and methodological complexes in the disciplines, specifically, at the end of the academic year.

3. All students would be accessed to the delivery of the control standards irrespective of their attendance, partial attendance or non-attendance of classes.

4. Students who would attend classes in the discipline "Increasing sportive mastering" delivered at the Department of the physical culture and provision of security of life of the Moscow State Psychological and Pedagogical University (MSPPU) are exempted from attending classes in "Physical culture" and "Applied physical culture" and delivery of the control tests since they would receive a specialized specific sports load in these classes.

According to the all mentioned above, we have elaborated and used the following didactical units of the work programs in the framework of implementation of the federal state educational standards 3 and $3+$ of the higher professional education for the disciplines "Physical culture":

1. General physical training - 160 academic hours.

2. Volleyball - 48 academic hours.

3. Basketball - 48 academic hours.

4. Football - 48 academic hours.

5. Light athletics -48 academic hours.

6. Professional applied physical training - 48 academic hours.

In agreement with the competence psycho-pedagogical approach and the presented didactical units, we have designed and introduced in practice of the Department of the physical culture and provision of security of life of the Moscow State Psychological and Pedagogical University (DPCPSL of MSPPU) the following regulatory and diagnostics actions, a total number of 16 standards:

1. Standards in general physical training and light athletics (7 indicators).

2. Standards in volleyball ( 3 indicators).

3. Standards in basketball ( 3 indicators).

4. Standards in football ( 3 indicators).

The regulatory and diagnostics procedures in the section of the didactical unit "Professional applied physical culture" have not been executed because of the fact that this discipline has not been studied by the students at the moment of this research, although there are 6 more standards envisaged in the work programs.

In accordance with the psycho-pedagogical approach to the regulatory and diagnostic procedures, we have provided students with free choice of standards according to their own internal preferences. The freedom of choice of the students in their preferences, when delivering these or those standards, has only been limited with a point-rating system introduced in the University. According to this system, they have to get at least 10 points in average in the 10 standards on their choice.

\section{Findings}

Attendance of classes in the disciplines "Physical culture" and "Applied physical culture", a number of students, who belong to a special medical group, a number of students, who attended during the semester a discipline "Improving sports skills", and a number of students, who received an automatics credit and thus did not participate in the regulatory and diagnostic procedures became one of the basis for the research. The distribution of students is presented in the Table 1.

Therefore, according to the distribution of students by the study of the disciplines "Physical culture" and "Applied physical culture", they divided about equally between those, who attended practical and lecture classes and received an automatic credit for these 
disciplines, and those, who on some reasons have not received an automatic credit and have to pass the procedure of the regulatory diagnostics (respectively, $47 \%$ and $53 \%$ ). A number of students related to a special medical group in a total number of students has been at the level of $7 \%$ only (28 people). It directly testifies that DPCPSL of MSPPU is carrying out the adequate work in the inclusion of students with some deviations in the health conditions into the general trend of the improving physical culture and health-improving work with students.

Table 1. The distribution of students by attendance.

\begin{tabular}{|l|c|c|}
\hline \multicolumn{1}{|c|}{ Indicators } & $\begin{array}{c}\text { Number of } \\
\text { students (n=384) }\end{array}$ & Ratio, \% \\
\hline A number of girls & 283 & $74 \%$ \\
\hline A number of young men & 101 & $26 \%$ \\
\hline A number of students in the special medical group & 28 & $7 \%$ \\
\hline $\begin{array}{l}\text { A number of students, who attended the discipline } \\
\text { "Improving sports skills" }\end{array}$ & 12 & $3 \%$ \\
\hline $\begin{array}{l}\text { A number of students, who received an automated } \\
\text { credit (total) }\end{array}$ & 181 & $47 \%$ \\
\hline $\begin{array}{l}\text { A number of students, who received an automated } \\
\text { credit (girls) }\end{array}$ & 128 & $71 \%$ \\
\hline $\begin{array}{l}\text { A number of students, who received an automated } \\
\text { credit (young men) }\end{array}$ & 53 & $29 \%$ \\
\hline $\begin{array}{l}\text { A number of students, who passed through } \\
\text { standards (total) }\end{array}$ & 203 & $53 \%$ \\
\hline $\begin{array}{l}\text { A number of students, who passed through } \\
\text { standards (girls) }\end{array}$ & 155 & $76 \%$ \\
\hline $\begin{array}{l}\text { A number of students, who passed through } \\
\text { standards (young men) }\end{array}$ & 48 & $24 \%$ \\
\hline
\end{tabular}

According to the Table 2, it is identified that in percentage terms there is a prevalence of female students both in the total number of students, and among those, who have been automatically credited or had to pass the regulatory diagnostics for getting a credit (respectively, 74\%, 71\% and 76\%). Meanwhile, a number of male students has also been rather evenly distributed by these indicators $-26 \%, 29 \%$, and $24 \%$. It provides us with a possibility to argue that there are no gender discrepancies in the emotional and volitional preferences in terms of the disciplines "Physical culture" and "Applied physical culture".

According to the psycho-pedagogical approach to the regulatory diagnostics procedures, the preferences of students (male and female) when passing the standards in general physical readiness and light athletics have been distributed as follows in the Figures 1 and 2.

Based on the Figures 1 and 2, and also on the general number of students in the total number of those, who passed the standards for girls $(n=155)$ and young men $(n=48)$, the basic preferences among girls have been the standards of the general physical readiness (swinging a press for 1 minute - 153 students) and jumping with jump rope (155 students), and also one of the standards of the light athletics - a long jump from the place (110 students). The male students preferred jumping with jump rope (46 students), and a standard of the light athletics - a long jump from the place (48 students). From the light athletics cycle, the most unpopular among both the girls and young men, have been running the 100 meters (no one wanted to do it) and running $1 \mathrm{~km}(28$ girls and 9 young men have decided to pass this standard). Among girls, the standards of the medium popularity have been the following: the general physical readiness standards - squatting on one leg (a right leg - 58 students, a left leg - 61 students), and the light athletics standards - a shuttle run 10x10 (99 students). Among young men, it has been squatting on one leg (a right leg - 34 
students, a left leg - 35 students), swinging a press for 1 minute -39 students of the standards of the general physical readiness, and just one standard for the light athletics - a shuttle run $10 \times 10$ (39 students).

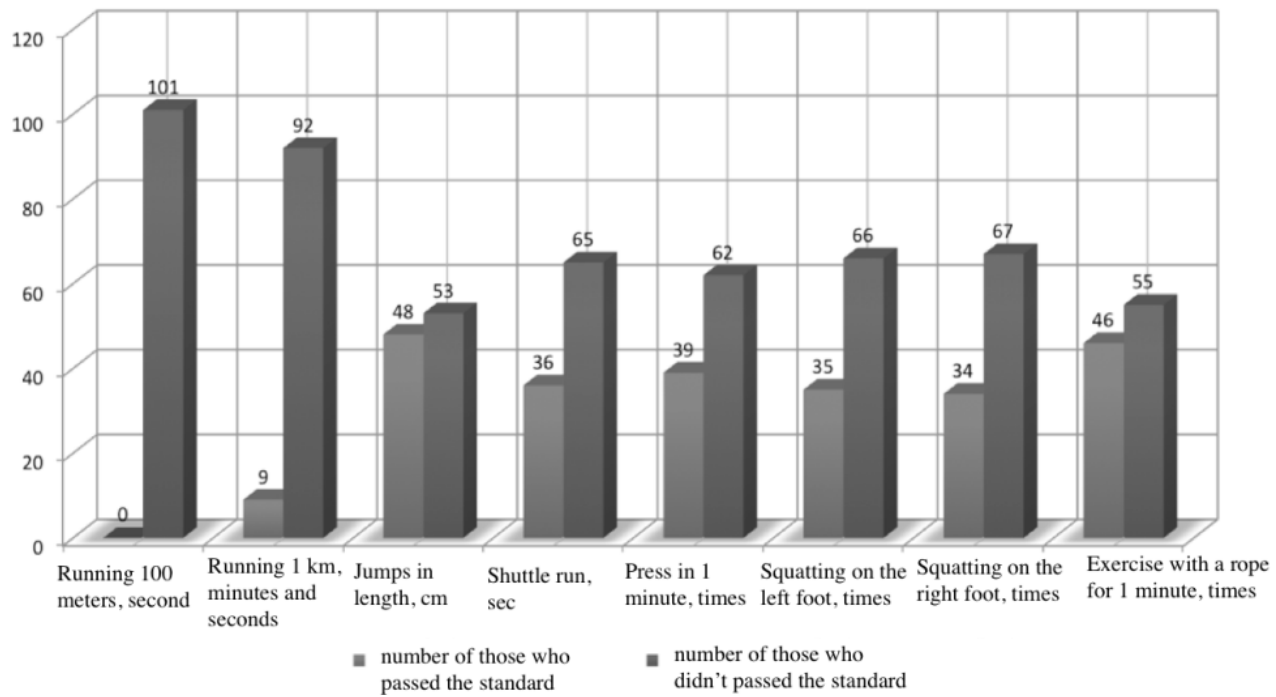

Fig. 1. Distribution of preferences in passing general physical readiness and light athletics standards (young men).

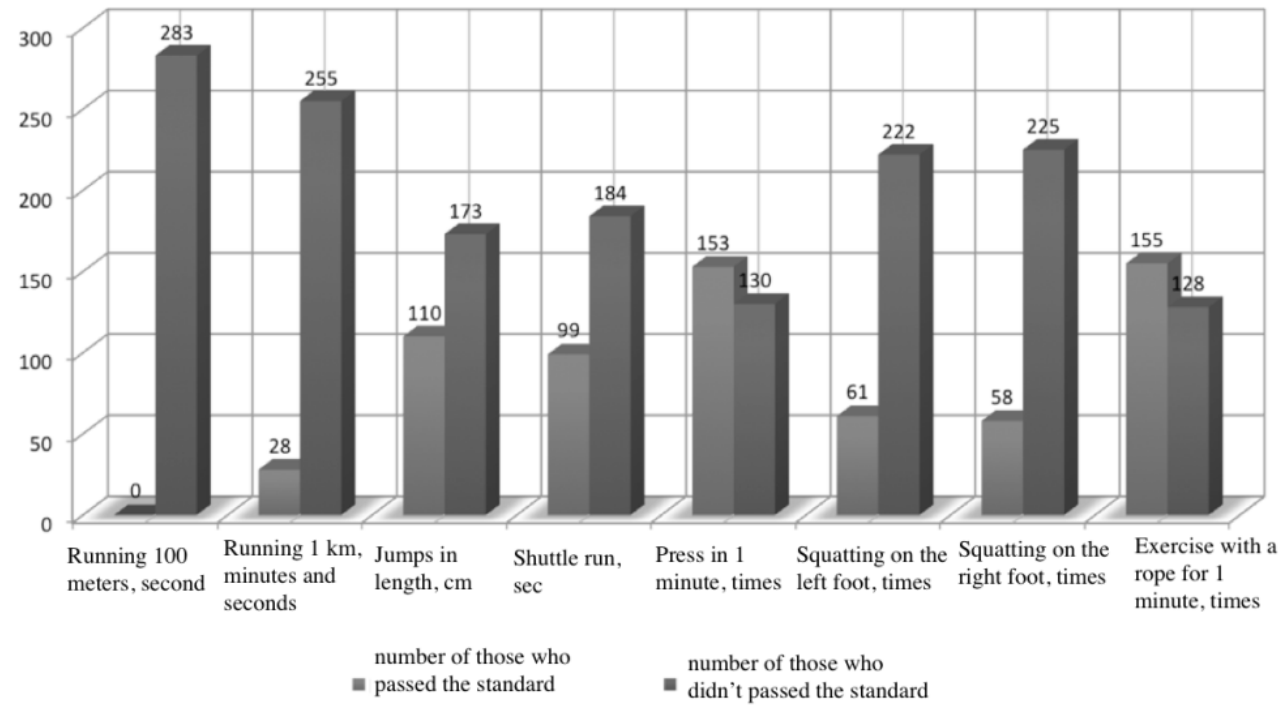

Fig. 2. Distribution of preferences in passing general physical readiness and light athletics standards (girls).

There is a possibility for making a preliminary conclusion that basic preferences in their totality among both female and male students are the standards of the general physical readiness at the expense of the standards of the light athletics.

Further, according to the psycho-pedagogical approach to the regulatory and diagnostics procedures, the preferences of students (girls and young men) in passing the standards in volleyball have distributed as follows (Figures 3 and 4): 


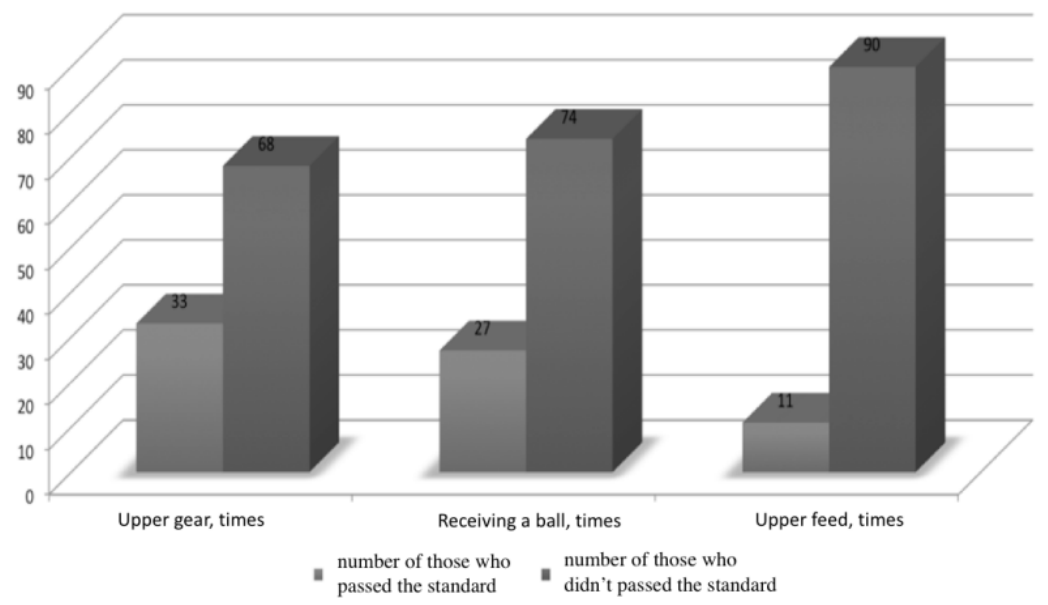

Fig. 3. Distribution of preferences in passing the standards in volleyball (young men).

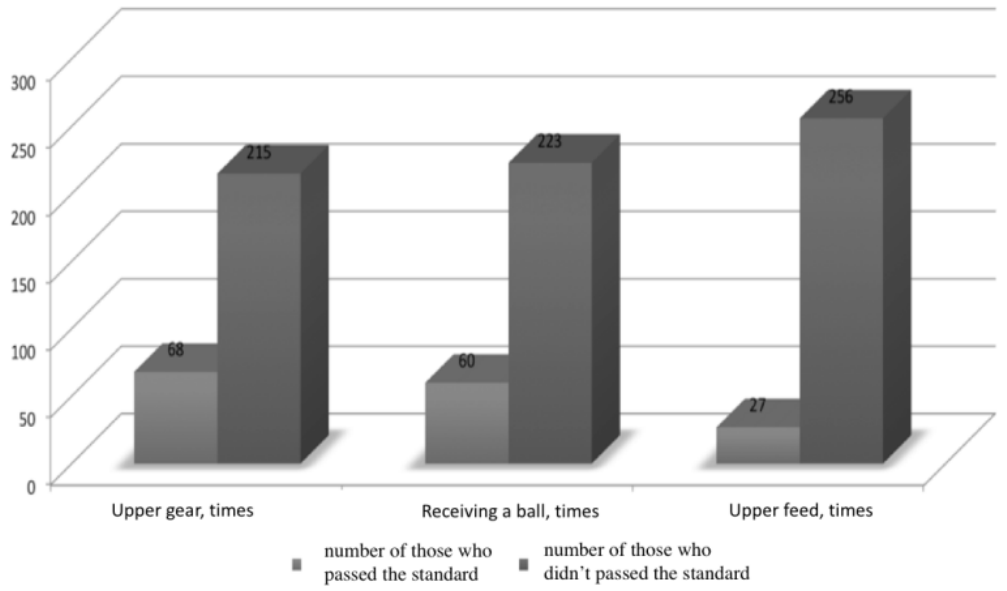

Fig. 4. Distribution of preferences in passing the standards in volleyball (girls).

Based on the figures 3 and 4, among girls, top passing the ball (68 students) and receiving the ball (60 students) have been the basic preferences in the regulatory diagnostics of the preparedness of students in the didactic unit "Volleyball" of the work programs of the disciplines "Physical culture" and "Applied physical culture". Feeding the ball have been the unpopular standard in the volleyball training ( 27 students). For the young men, the preferences have distributed the same way. Top passing the ball (33 students) and receiving the ball (27 students) have been the most preferable exercises. And like girls, feeding the ball preferred to execute just 11 young men, and it has been the most unpopular standard.

Based on the number of those students, who have chosen to pass the standards of the didactic unit "Volleyball" in the total number of those girls and young men, who passed the regulatory diagnostics ( 68 female students in their total number of 155, and 33 students of their total number of 48 people), we can preliminary conclude that the volleyball standards had a medium level of popularity among girls, and a high popularity among young men.

Also, in accordance with the psycho-pedagogical approach to the regulatory and diagnostics procedures, in passing the standards in basketball the preferences of students (girls and young men) have distributed as follows (Figures 5 and 6). 
Based on the Figures 5 and 6, the same standard, both for the male and female students, has been the priority one in the regulatory diagnostics of the didactic unit "Basketball" of the work programs of the disciplines "Physical culture" and "Applied physical culture". It has been accurate throw from a place that has been chosen by 60 girls and 28 young men for obtaining a credit. Keeping the ball three laps has been less popular, as only 23 girls and 10 young men have chosen this standard for the passing attestation. The standard of the attack with conducting has appeared to be the most unpopular, since no one has decided to pass this standard.

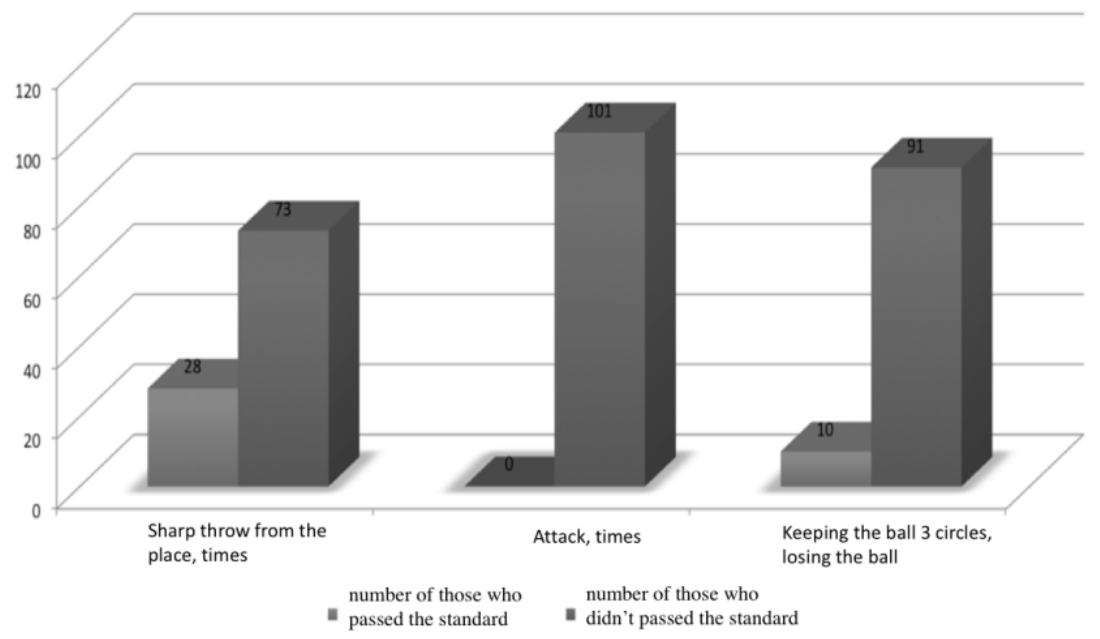

Fig. 5. Distribution of preferences in passing the standards in basketball (young men).

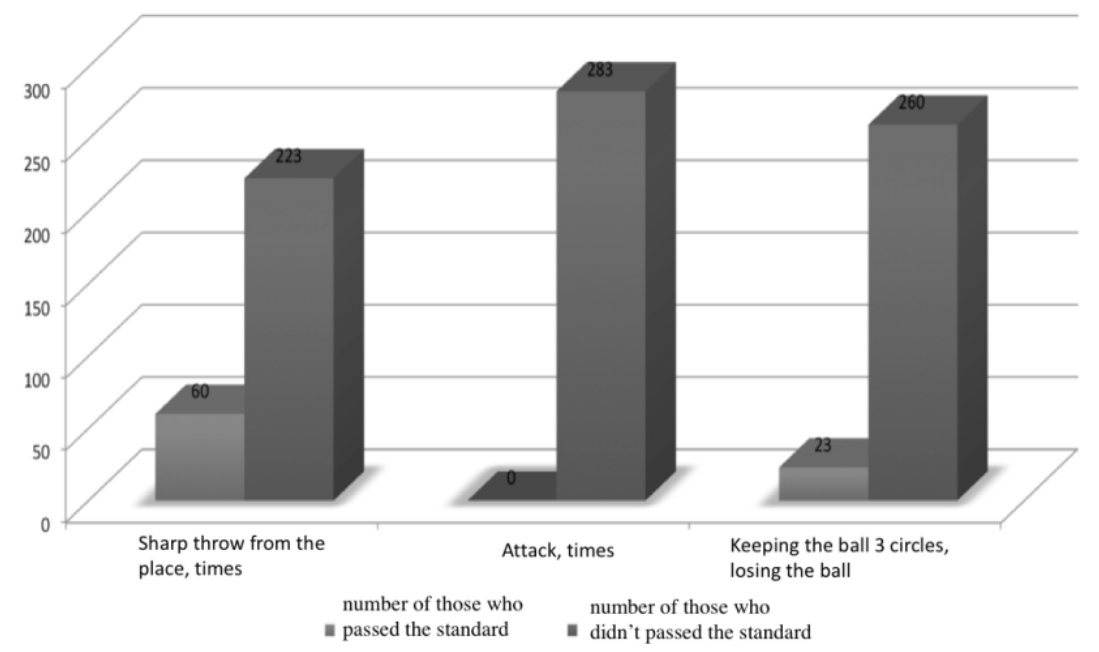

Fig. 6. Distribution of preferences in passing the standards in basketball (girls).

In general, there have been just a minor quantity of those, who have chosen for the regulatory diagnostics of their physical and sports readiness the didactic unit "Basketball" ( 60 female students of the general set of 155 and 28 male students of the general set of 48 students passing the tests), and it is possible to make a preliminary conclusion that this didactic unit is less popular among the students' youth. 
At last, according to the psycho-pedagogical approach to the regulatory and diagnostics procedures, in passing the standards in football the preferences of students (girls and young men) have distributed as follows (Figures 7 and 8).

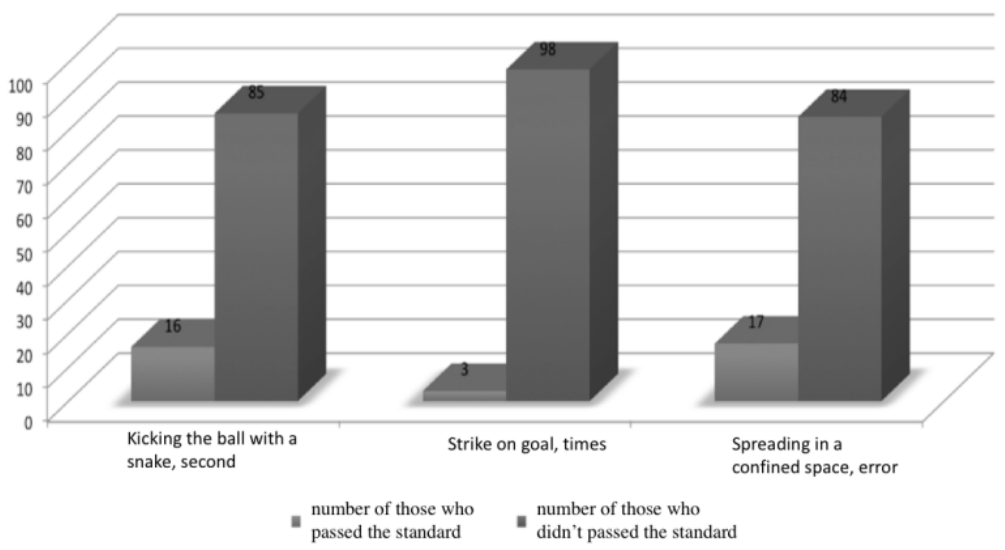

Fig. 7. Distribution of preferences in passing the standards in football (young men).

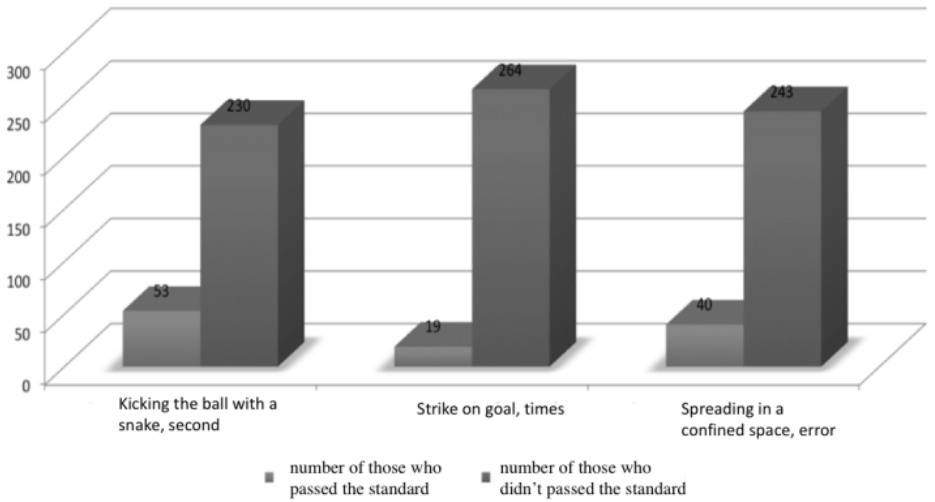

Fig. 8. Distribution of preferences in passing the standards in football (girls).

Based on the Figures 7 and 8, two standards, both for the male and female students, have been the most popular in the regulatory diagnostics of the didactic unit "Football" dribbling (53 girls and 16 young men of those, who passed the test), and passes in a limited space (40 and 17 students respectively). Such standard as "a goal kick" happened to be less popular, since just 19 girls and 3 young men have decided choosing it for getting a credit.

In total, there have been even less number of students, who have decided to choose for the regulatory diagnostics of their physical and sports fitness the didactic unit "football": in general, just 53 girls of 155 , and 17 young men of 48 . Of that, we can make a preliminary conclusion that this didactic unit had a low popularity among the students' youth in MSPPU.

\section{Conclusion}

Therefore, based on the results of our research, we can make the following conclusions:

1. As a result of the calculated ratio, when applying the psycho-pedagogical approach to the teaching of disciplines "Physical culture" and "Applied physical culture", only half of students gets automatic credit on the basis of the results of their study. 
2. According to the use of the psycho-pedagogical approach, students of MSPPU mostly prefer the standards of the general physical fitness in the regulatory diagnostics of their physical and sports readiness. Then follow didactical units of "Volleyball" and "Light athletics", and, at last, less popular are didactic units "Basketball" and "Football".

At the end, it is possible to make a general conclusion about necessity to devote a careful attention to the theoretical and educational, and motivation and value components of the physical culture and sports sides of life of the MSPPU students for the whole period of their study, and introduction to this process, in addition to the regulatory indicators, the indicators of physical states that would demonstrate the dynamics of personal achievements of the students. Popularization of both the overall significance of the disciplines "Physical culture" and "Applied physical culture", and particular didactic units as components of these disciplines, specifically - the units "Basketball" and "Football" - is also needed.

In the meantime, considering that professional self-determination of students has a complicated and contradictory nature, they need an improvement of their literacy in specifics of their future specialty, its competences, correlations between the individual psycho-physical abilities with the requirements of the future profession, methods of improvement of the professionally important peculiarities and individual qualities with the means of the physical culture and sports. All these should be achieved at the time of study in the higher educational establishments. The consideration of individual psychological peculiarities of students in the process of uninterrupted physical culture training opens new perspectives for further improvement of the individually oriented psycho-physical preparedness to the professional activity.

\section{References}

1. A. S. Boldov, Scientific notes of University named after P. F. Lesgaft, 4, 146 (2017)

2. A. S. Boldov, Actual problems of ecology and human health: Materials of the I international scientific-practical conference (FGBO VO ChSU, Cherepovets, 2013)

3. A. S. Boldov, A. V. Gusev, and V. Yu. Karpov, Materials of economic and social development (book of proceedings) of the 25th International Scientific Conference On Economic And Social Development - XVII International Social Congress” (Moscow, 2017)

4. A. V. Gusev, Actual problems of ecology and human health: Proceedings of the I International Scientific and Practical Conference (FGBO VO ChSU, Cherepovets, 2013)

5. Sorbonne Joint Declaration, Joint declaration on harmonisation of the architecture of the European higher education system (Paris, 1998)

6. The Order of the State Committee on Higher Education of Russia "On the approval of an exemplary curriculum on physical culture and instructions on the organization and maintenance of the work of the departments of physical education of universities" $N$ 777 of 26.07.1994 (Moscow, 2018)

7. The order of the Ministry of Education of Russia "On the organization of the process of physical education in educational institutions of primary, secondary and higher vocational education" from 01.12.99 №1025 (Moscow, 2018)

8. T. G. Vizel, Prevention, diagnosis and correction of deviant adolescent behavior: the psychological-pedagogical approach (http://psyera.ru/profilaktika-diagnostika-ikorrekciya-otklonyayushchegosya-povedeniya-a-podrostkov-psihologo_7344.htm) 